\title{
De la arquitectura religiosa utópica a la evangelización en los no-lugares
}

From utopic religious architecture to evangelization in non-places

Eloi Aran Sala · Facultat de Teologia de Catalunya (España)

https://doi.org/10.17979/aarc.2013.3.0.5097

\section{RESUMEN}

Buena parte de la arquitectura religiosa contemporánea está constituida por iglesias parroquiales. El término parroquia equivale etimológicamente a vecindad, aunque tiene la connotación bíblica de comunidad extranjera, emigrante o peregrina. Esta dimensión escatológica de orientación hacia Cristo y la Parusía es la utopía cristiana. En contraste, la arquitectura utópica de la sobremodernidad, en tanto que no-lugar, resulta a priori no-religiosa. Sin embargo, hoy podemos analizar propuestas que acompañan la fe de los usuarios en el tránsito y quehacer cotidiano, en diálogo con las tradicionales cruces de término, humilladeros y ermitas.

\section{ABSTRACT}

Most buildings of contemporaneous religious architecture are parochial churches. The term parish etymologically means neighborhood, although it also has the biblical connotation of foreign, migrant or pilgrim community. This eschatological dimension of tending towards Christ and the Parousia is the Christian utopia. In contrast, postmodern utopic architecture, in the sense of noplace, is a priori non-religious. However, today we can analyze proposals that accompany the faith of the users in the everyday movement and live, in dialog with the traditional road crosses, outdoors devotional altars and hermitages.

\section{PALABRAS CLAVE}

Arquitectura religiosa; no-lugar; Jenseits im Viadukt; capilla de San Francisco de Javier; Barcelona.

\section{KEYWORDS}

Sacred architecture; non-places; Jenseits im Viadukt; Saint Francis Xavier Chapel; Barcelona. 


\section{LOS NO LUGARES, ESPACIOS DEL ANONIMATO}

Buena parte de la arquitectura religiosa realizada a lo largo de los siglos XX y XXI — salvo algunos casos paradójicamente significativos como las nuevas catedrales, templos expiatorios o los oratorios - son iglesias parroquiales. De este hecho, cabría decir que la evangelización se sigue desarrollando bajo un esquema territorial, donde prevalece la implementación y visualización de una comunidad cristiana local. En efecto, el término parroquia proviene etimológicamente del griego par-oikía, que equivale a vecindad, aunque también tiene otra connotación en la Biblia griega de los LXX, donde la Iglesia es considerada como una comunidad extranjera, emigrante o peregrina, tal como se muestra en la Carta de Diogneto: «[Los cristianos] Habitan en su propia patria, pero como forasteros; toman parte en todo como ciudadanos, pero lo soportan todo como extranjeros; toda tierra es extraña a su patria, pero están en toda patria como en tierra extraña» ${ }^{1}$.

Esta segunda acepción del término parroquia, entendida como grupo de creyentes que peregrina hacia Cristo, abre la puerta a la comprensión de la arquitectura religiosa como ideal o utópica, a saber: aquella que apunta a una realidad que no tiene lugar, que no cabe sino en la esperanza escatológica de la Parusía. La sugerente imagen de la Jerusalén Celestial (Ap 21-22), la orientación de la asamblea cristiana hacia el este, o la representación del Pantocrátor en los ábsides de tantas iglesias, son respuestas visuales de la utopía cristiana²

Hoy en día, la comprensión de lo utópico debe complementarse con la reflexión expuesta en «Los no lugares. Espacios del anonimato» ${ }^{3}$. Este ensayo antropológico apunta tres excesos o desbordamientos propios de la sobremodernidad actual: el exceso temporal, el exceso espacial y el exceso del individualismo. El exceso de tiempo se muestra en la crisis de la idea de progreso y en una sociedad que vive acelerada, a golpes de acontecimientos. El exceso espacial se muestra en la crisis de la idea de lugar antropológico, antaño tan presente en la mitología de la fundación de las ciudades ${ }^{4}$, así como en la relación anónima y contractual de los espacios de tránsito. El exceso del individualismo se muestra en la disolución del referente comunitario y en la creación de una identidad globalizada.

Como consecuencia de las características expuestas nos encontramos con que los no-lugares son, a priori, espacios no-religiosos en tanto que, siguiendo con las acepciones etimológicas, no re-ligan (re-ligare), no releen (re-legere) y no re-eligen (re-elegere). En estos espacios - tales como el asiento de un espacio de embarque, el vagón de un tren, la autopista, las salas de espera, etc. - la persona no crea vínculos, ya que se trata de espacios de tránsito y de ocupación efímera. Por lo que respeta a la re-lectura, ésta se da solamente como un entretenimiento o como dato pasajero, sin ahondar en su significado, por ejemplo en los nombres de las estaciones de metro. Si las antiguas ciudades buscaban el descendimiento de las señales del cosmos en la tierra, ahora nos encontramos con señalizaciones que no indican un norte, un cielo o un infierno, sino nuevas rutas para la realización humana en el consumo, ya sea en el departamento de deportes, de bisutería o en la abundancia del supermercado situado en el mundus, en el sótano del centro comercial ${ }^{5}$. Finalmente, tampoco se da un re-elegir, ya que en la perspectiva individualista del anonimato se da la elección de productos pero no la celebración de una opción de vida, pues esta no cabe o parece extraña al no-lugar.

A pesar de esta aparente carencia religiosa de los nolugares, encontramos elementos de la arquitectura religiosa occidental que se sitúan en estos espacios, tales como cruces de término o también ermitas situadas en los caminos. Estos elementos tradicionales han tenido también su versión contemporánea en capillas situadas en los aeropuertos, en campus universitarios, hospitales, oratorios en autopistas y demás tipologías de equipamientos o lugares de tránsito, por no hablar de rutas que son ya por sí mismas un espacio sagrado — como el Camino de Santiago o el Camino Ignaciano- y de grandes implosiones celebrativas de carácter efímero como las Jornadas Mundiales de la Juventud (JMJ).

\section{JENSEITS IM VIADUKT}

Yendo ya a analizar algún caso concreto de espacio religioso en los no-lugares, creo interesante presentar el proyecto «Jenseits im viadukt» ${ }^{6}$, que podríamos traducir como más allá, en el viaducto. Se trata de un espacio para jóvenes, ofrecido desde la diócesis católica de Zurich (Suiza), diseñado por Peter Kuwikowski y Esther Bormann en 2010.

El proyecto se emplaza debajo de los pórticos de un viaducto a las afueras de la ciudad, muy cerca de una estación de metro, al lado de una incineradora y en el contexto de un barrio de carácter obrero y multicultural 

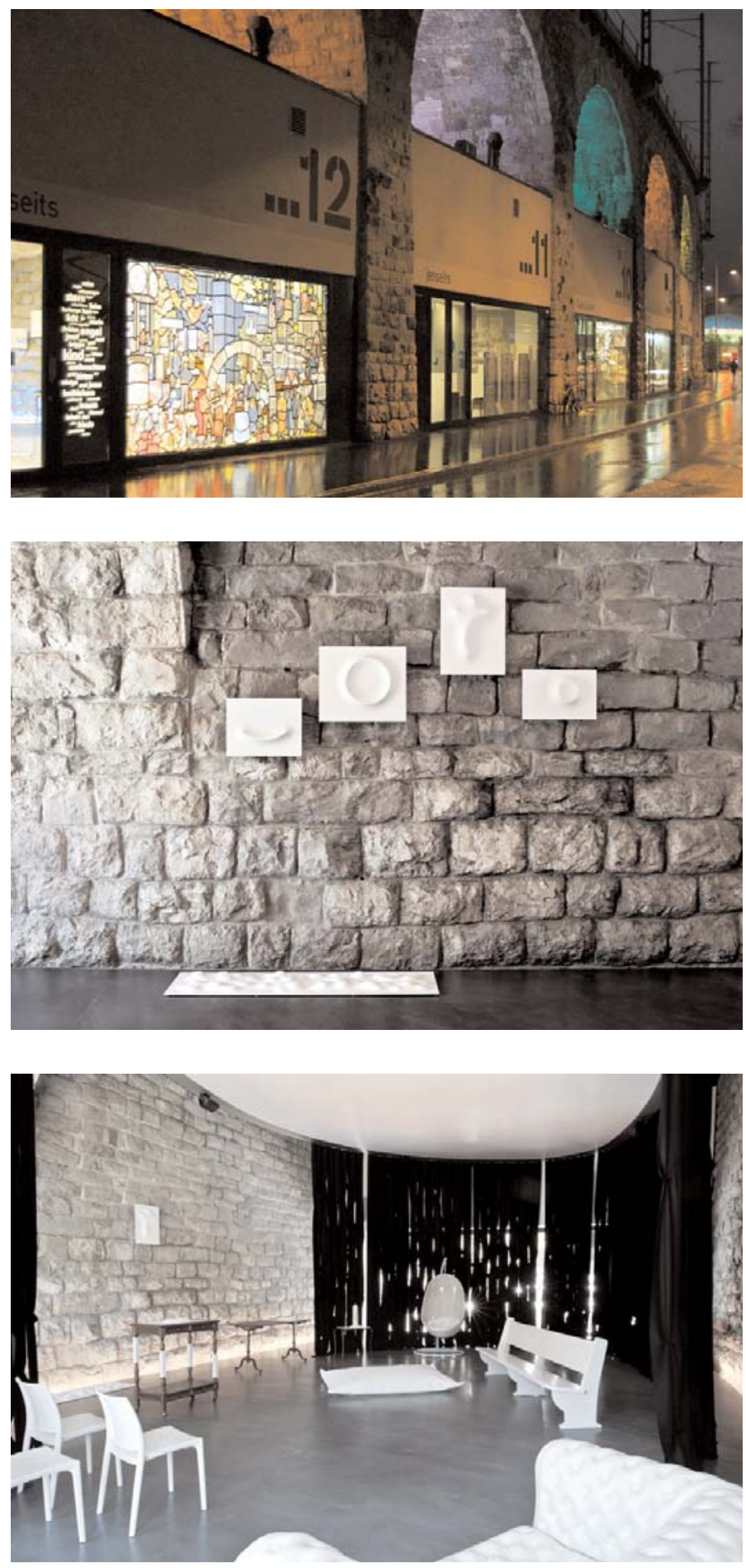

Fig. 01. Peter Kuwikowski y Esther Bormann, Jenseits im Viadukt, Zurich (Suiza), 2010; imagen exterior.

Fig. 02. Imagen trinitaria.

Fig. 03. Espacio polivalente. 
(Fig. 01). Este espacio no tiene voluntad de significarse como religioso exteriormente, y las referencias confesionales de su interior son más bien escasas, mostrándose más como una sugerencia que como una carta de presentación; véase, por ejemplo, el retablo tripartito que representa la Trinidad, puesto discretamente en uno de los muros (Fig. 02). Esta identidad blanda, típicamente postmoderna, queda acentuada por el carácter reversible y polivalente de los espacios interiores, donde se puede celebrar tanto un acto religioso como un concierto o una exposición. Para conseguir esta división ambiental se ha optado por colgar un falso techo oval de una de las la bóvedas de cañón del viaducto, de donde pende perimetralmente un cortinaje negro que permite separar el espacio de posibles miradas exteriores (Fig. 03).

De este proyecto podemos destacar varios aspectos. Por una parte, la oportunidad que ofrece para la evangelización un espacio urbano residual, debajo de un viaducto. Por otra, la presentación de un espacio abierto al diálogo en sus múltiples ofertas funcionales, que es la forma como el Concilio Vaticano II habló de evangelización? ${ }^{7}$ Y finalmente, recuperar el espíritu del homo ludens que reclamaba Romano Guardini y que fue puesto en práctica en la conocida Sala de los Caballeros del Castillo de Rothenfels-am-Main por él mismo, junto con Rudolf Schwarz, en 1928: "Vivir litúrgicamente (...) es convertirse en una obra de arte, que se realiza ante Dios Creador, sin ninguna otra finalidad que ser y vivir en su presencia: es cumplir las palabras del Maestro Divino que nos ordenan que nos hagamos como niños (Mc 19,15), es renunciar a la artificiosa y falsa prudencia de la edad madura que en todo pretende encontrar un resultado práctico, y jugar como David lo hacía ante el Arca de la Alianza (2 Sam 6,12-16)»?

\section{LA CAPILLA DE SAN FRANCISCO JAVIER}

El segundo ejemplo que quiero presentar como arquitectura religiosa en los no-lugares es la capilla de San Francisco Javier del Colegio del Sagrado Corazón de Jesús de la calle Caspe de Barcelona, obra de Carlos Francesch y Araceli Manzano, que recibió el premio FAD (Fomento de las Artes Decorativas) de interiorismo el mismo año de su realización (2006). Si en el caso anterior hablábamos del espacio litúrgico en relación con el juego, en esta ocasión el centro educativo ha hecho un esfuerzo por no disolver el espacio sagrado en un recinto con otra finalidad (Fig. 04).
El acceso se realiza a través de un vestíbulo bajo con falso techo de madera, y una pared de corcho de color verde donde se pueden colgar los elementos de la catequesis escolar. Posteriormente, el techo se eleva y se accede a un espacio central blanco, sin aristas ni ejes, donde dos superficies curvas — pared y techo- abarcan el espacio sin limitarlo, ya que no hay una entrega directa, sino que se deja un foso para la iluminación artificial indirecta de diferentes colores e intensidad, como quien apunta o señala al cielo sin tocarlo. El revestimiento del pavimento es de madera clara, mientras que la parte baja de las paredes es de madera oscura y es usado a modo de armario técnico — proyector, sonido, almacén-, proporcionando la calidez necesaria en contacto con los usuarios (Fig. 05).

En una perspectiva en diagonal al acceso, la vista es atraída por una entrada de luz natural vertical, junto a una cruz esbelta que enlaza el plano de tierra —el plano del mundo - con el techo que apunta al límite - el plano de lo trascendente- - La utilización de la iluminación y de la luz natural hace hincapié en los conceptos que interesa reforzar. Una ventana de proporción alargada - luz natural — separa las dos superficies curvas, a la vez que deja a contraluz la mitad del perfil de la cruz como mediadora entre estos dos ámbitos. En el ambiente general de penumbra en el que la sala permanece cuando se apaga la iluminación general, el color blanco de los paramentos así como la iluminación de los diferentes planos diferencian cada uno de los elementos constructivos del espacio.

\section{UN DÍPTICO Y UN RECUERDO}

El último ejemplo para traer a colación lo presento a modo de díptico: un breve diálogo entre la ermita del barrio de Bellvitge y la capilla de la nueva terminal del aeropuerto de Barcelona, ambas en el municipio barcelonés de L'Hospitalet del Llobregat y a escasa distancia entre sí. La ermita de Santa María de Bellvitge recibe su nombre de la contracción del catalán bell-viatge —que significa bello o buen viaje-, y hay constancia de su presencia desde el siglo XII, aunque se supone que existía ya en el siglo XI. De apariencia y construcción tosca, esta construcción es un ejemplo de presencia religiosa en un lugar de tránsito. Franqueada hoy en día por una gran infraestructura de tránsito rodado, situada bajo la sombra de un hotel firmado por Richard Rogers y los bloques de viviendas de trece plantas del barrio que 


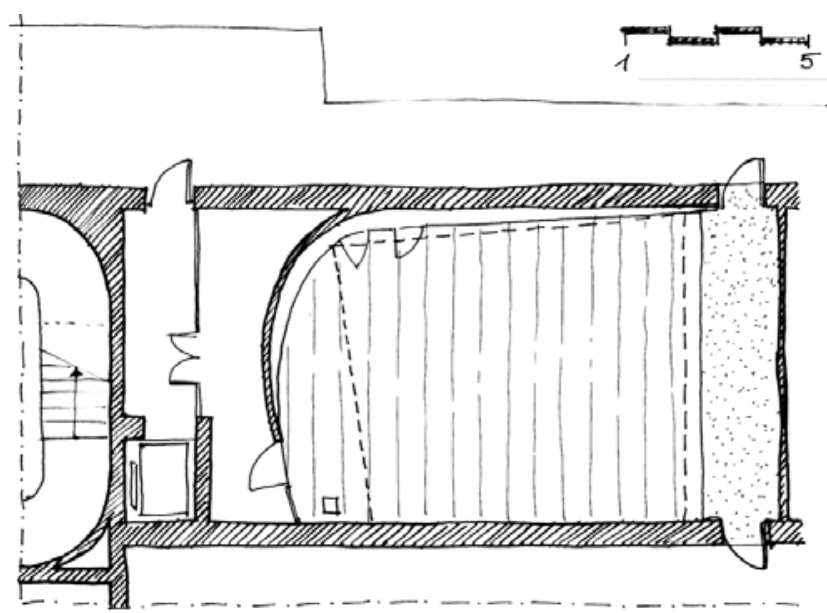

Fig. 04. Carlos Francesch de Herralde y Araceli Manzano Martín-Caro, Capilla de San Francisco Javier, Colegio de los pp. Jesuitas, Barcelona, 2006; planta. Fig. 05. lluminaciones.
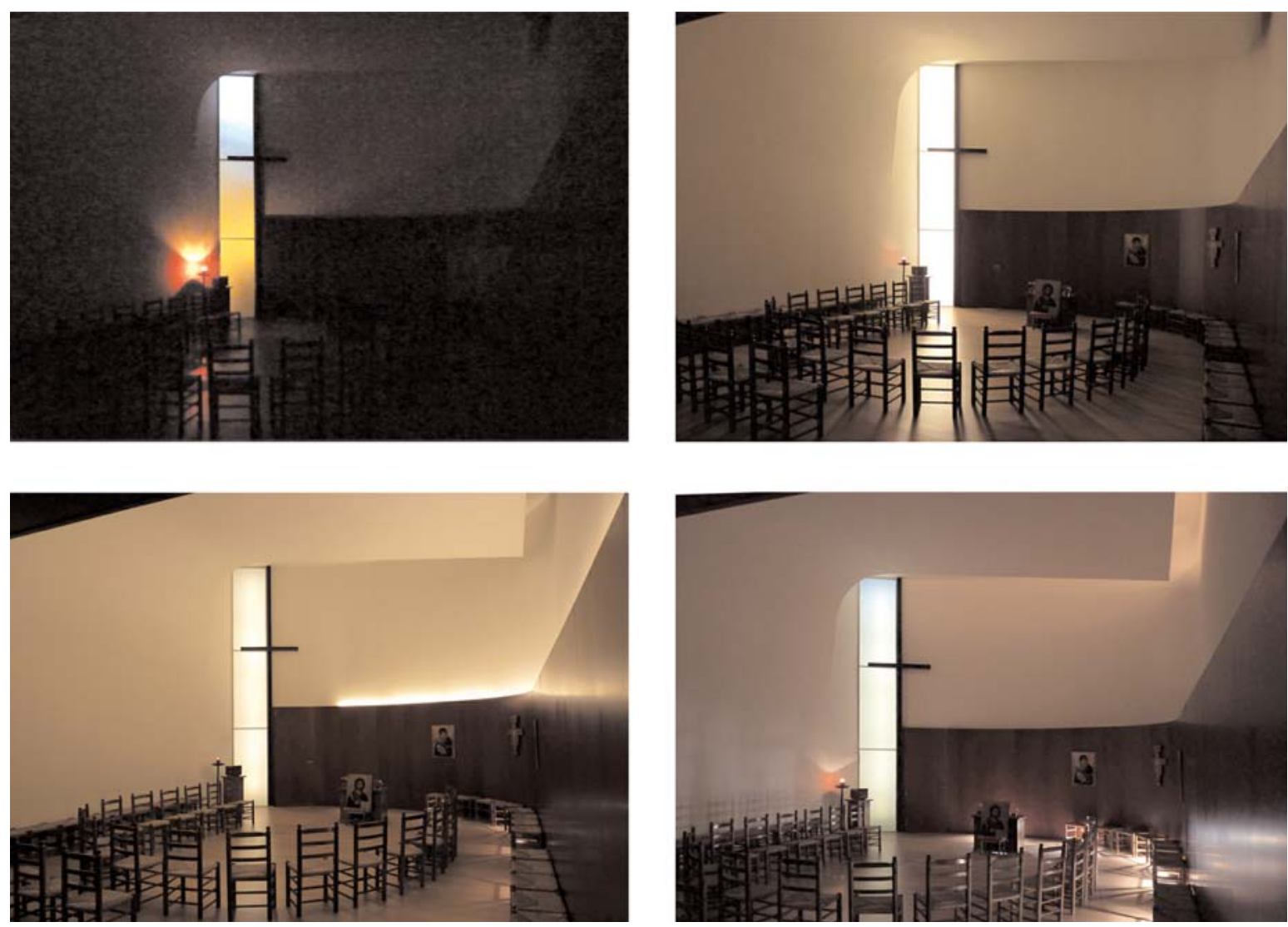


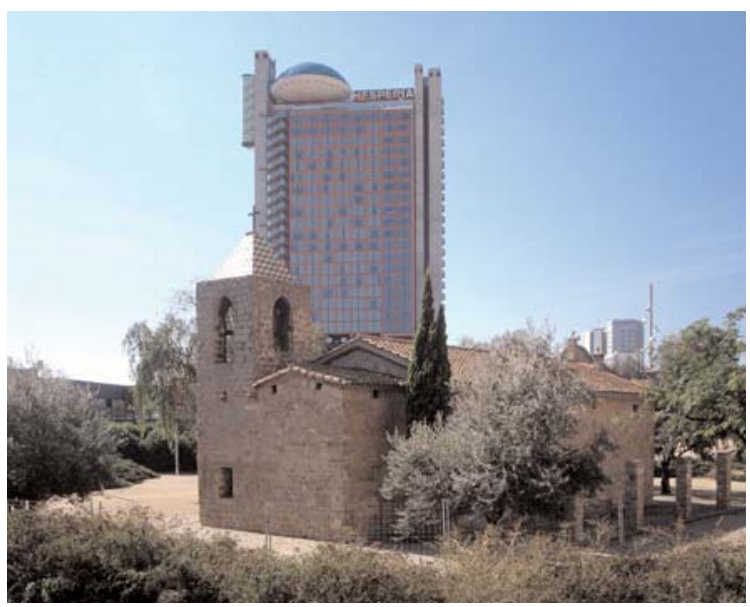

Fig. 06. Ermita de Santa María de Bellvitge, L'Hospitalet del Llobregat (Barcelona), s. XII.

lleva su nombre, esta pequeña construcción ha quedado relegada de su función original, pero preside cual ruina romántica el espacio ajardinado del suburbio, siendo muy estimada por sus habitantes (Fig. 06).

En contraposición, se encuentra la que tendría que cumplir las funciones como nueva ermita de Bellvitge: la capilla de la nueva terminal del aeropuerto de Barcelona, obra de Ricardo Bofill. Este espacio, aunque acabado con materiales más nobles, ocupa un sitio residual y escondido, al lado de una oficina turística y donde se podría haber dispuesto cualquier otro equipamiento. El espacio, aunque correcto, es de una neutralidad aséptica y apenas tiene nada a comunicar. Este hecho pone de manifiesto la falta de intencionalidad y de reflexión sobre lo que tendría que ser un espacio religioso en un aeropuerto. Seguramente, si desapareciera, apenas se la echaría en falta (Fig. 07).

Finalmente, no puedo dejar de hacer referencia a los no-lugares más certeros de nuestra época y de los cuales suele callar el discurso académico: los campos de refugiados. Se estima que más de cuarenta y un millones de personas habitan en lo que la ONGd Entreculturas ha definido como «no-land $»^{10}$, esas tierras de nadie donde se sobrevive de la ayuda exterior, dada la negativa de los gobiernos de los países donde se ubican para que sus usuarios puedan trabajar la tierra o crear empresas (Fig. 08). Es precisamente allí donde

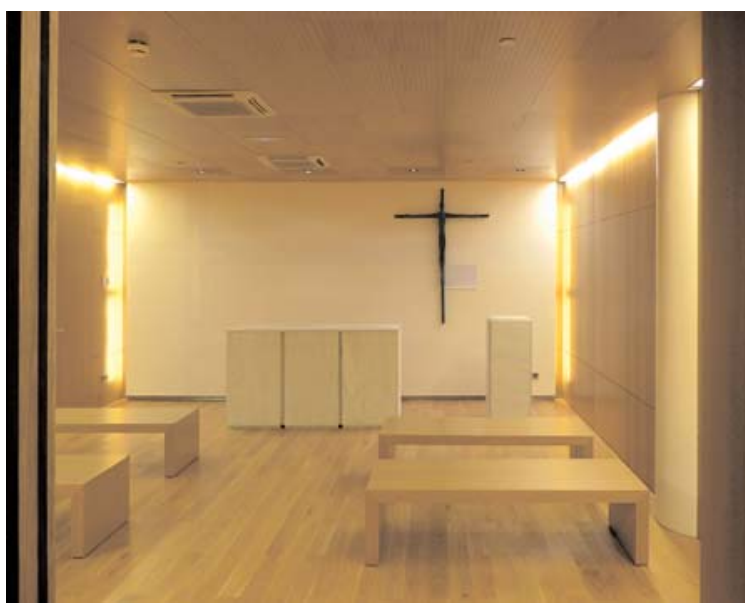

Fig. 07. Ricardo Bofill Leví, Capilla de la Terminal T1 del aeropuerto de Barcelona-El Prat, El Prat de Llobregat (Barcelona), 2009.

urge crear espacios de esperanza como imagen de lo que el papa Francisco desea para la Iglesia católica: que sea un hospital de campaña para tras una batalla que pueda sanar heridas ${ }^{11}$. Si la arquitectura religiosa de urgencia del siglo XX dio paso, en gran medida, a la arquitectura religiosa contemporánea — como fue el caso de Notre-Dame-du-Rancy, en los suburbios de las grandes ciudades o en la infinidad de parroquias alemanas de la posguerra-, ésta sigue inquiriendo una nueva respuesta de los arquitectos en los campos de refugiados de nuestro mundo.

\section{PROCEDENCIA DE LAS ILUSTRACIONES}

Fig. 01-03. Betty Fleck/Jenseits.

Fig. 04-07. Eloi Aran Sala.

Fig. 08. Crispin Baseka/JRS.

\section{NOTAS}

(1) Carta a Diogneto (cap. 5-6: Funk 1, 317-321). Las citas bíblicas que confirmarían esta interpretación son Ef 2,19: «Por eso, ya no sois extranjeros, no estáis ya fuera de vuestra tierra, sino que ahora compartís con el pueblo santo los mismos derechos, y sois miembros de la familia de Dios»; 1Pe 2,11: "Queridos hermanos, os ruego, como a extranjeros de paso por este mundo, que no deis lugar a los deseos humanos que luchan contra el alma»; Heb 11,13: «Todas estas personas murieron sin haber recibido las cosas que Dios había prometido; pero como tenían fe, las vieron de lejos y las saludaron reconociéndose a sí mismos extranjeros de paso por este mundo». Cf. 
también Casiano Floristán Samanés, Para comprender la parroquia (Estella: EVD, 1998).

(2) Cf. Louis Bouyer, Arquitectura y liturgia (Bilbao: Grafite, 2000); Joseph Ratzinger, El espíritu de la liturgia. Una introducción (Madrid: Cristiandad, 2005).

(3) «Los no lugares son tanto las instalaciones necesarias para la circulación acelerada de personas y bienes (vías rápidas, estaciones de enlace, aeropuertos) como los mismos medios de transporte o los grandes centros comerciales, o también los campos de tránsito prolongado donde hacen estancia los refugiados del planeta» (Marc Augé, Los no lugares. Espacios del anonimato. Barcelona: Gedisa, 2006, 41).

(4) Cf. Joseph Rykwert, La idea de ciudad (Madrid: Hermann Blume, 1985).

(5) «Nosotros hemos perdido todas las hermosas certezas sobre la forma y el funcionamiento del universo y ni siquiera sabemos si está en expansión o en contracción, si fue producido por una catástrofe o si se renueva constantemente. Esto no nos exime de buscar algún tipo de fundamento para la certeza en nuestros esfuerzos para dar forma al entorno humano. No es ya verosímil que nos encontramos este fundamento en el que los entendidos en cosmología están remodelando continuamente en nuestro entorno. Esto nos obligará a encontrar sentido dentro de nosotros mismos, en la constitución y en la estructura de la per- sona humana» (Rykwert, La idea de ciudad, 257).

(6) «Jenseits», con acceso el 1 de octubre de 2013, www.jenseitsimviadukt.ch/2011/de.

(7) «Daremos a este impulso interior de caridad, que tiende a convertirse en don exterior, el nombre, hoy común, de diálogo» (Pablo VI, Carta encíclica Ecclesiam Suam, 6 de agosto de 1964, $\left.n^{\circ} 76\right)$. «Por el diálogo hacemos presente a Dios entre nosotros, cuando nos abrimos al diálogo, nos abrimos nosotros mismos a Dios» (Juan Pablo II, «A representantes de religiones nocristianas (Madrás, 5/2/1986)», AAS 78 (1986): 769 ss; también en Ecclesia 22/02/1986: 32-33).

(8) Cf. María Antonietta Crippa, «Romano Guardini y Marie-Alain Couturier. Los orígenes de la arquitectura y del arte para la liturgia católica en el siglo XX», en Arquitecturas de lo sagrado. Memoria y proyecto, ed. Esteban Fernández-Cobián (A Coruña: Netbiblo, 2009), 178-205.

(9) Romano Guardini, El espíritu de la liturgia (Barcelona: Centre de Pastoral Litúrgica, 2006), 71.

(10) «No-land», con acceso el 1 de octubre de 2013, www.entreculturas.org/noland.

(11) «Papa Francisco: "Busquemos ser una Iglesia que encuentra caminos nuevos". Entrevista exclusiva», con acceso el 1 de octubre de 2013, www.razonyfe.org/images/stories/ Entrevista_al_papa_Francisco.pdf, 13. 


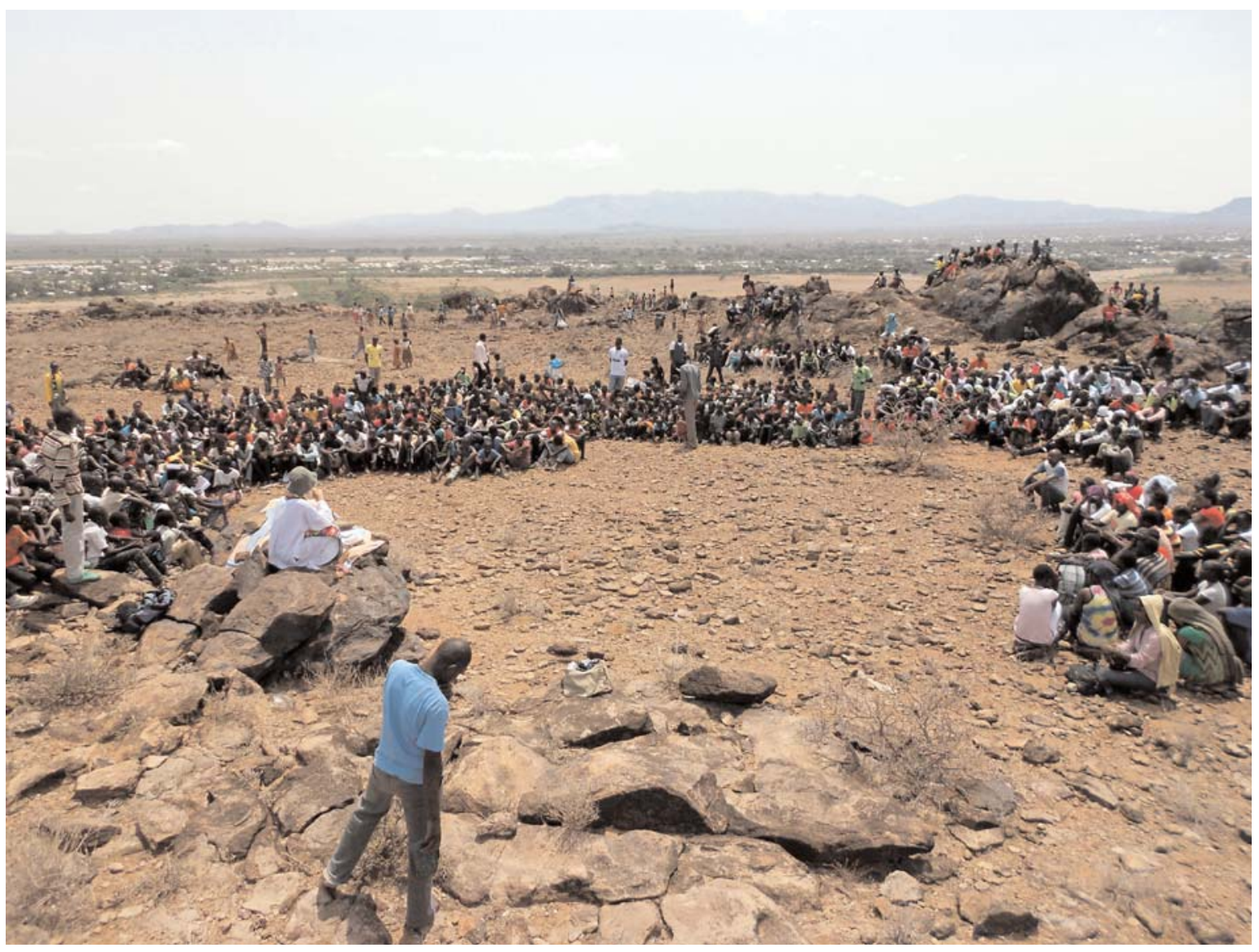

